\title{
Forecast of National Higher Education Scale Trend Based on GM $(1,1)$ Model
}

\author{
Feiyan Shen ${ }^{1 *}$, Mengxia Yang ${ }^{1}$, Wei Deng ${ }^{1}$, Sijia Zhong ${ }^{1}$ \\ ${ }^{1}$ School of Sichuan Agricultural University, Dujiangyan, Sichuan, 611830, China \\ *Corresponding author. Email: 1195834699@qq.com
}

\begin{abstract}
The three indicators of the number of schools, educational personnel and full-time teachers have a correlation with college size, which can be quantified. Therefore, by collecting data from the last five years in China, a grey forecasting model (GM) was used to predict the quantitative changes of these three indicators in the coming years and to propose targeted policies for implementation. The predicted values are analysed by residual tests for accuracy. The effectiveness of the policy is evaluated by passing the accuracy test.
\end{abstract}

Keywords: GM(1,1), residual tests, MATLAB

\section{INTRODUCTION}

According to the national education development statistics bulletin in 2019, China's gross enrollment rate in higher education was $51.6 \%$, officially entering the universalization stage [1]. General Secretary Xi Jinping pointed out at the National Education Conference that we should insist on running education on Chinese soil. The scale of higher education has always been a barometer of the development of higher education in a country, reflecting not only the scale and speed of development of higher education in a country, but also the relevance of higher education to politics, economy and culture in a country from a macro perspective. Therefore, the study of higher education scale has been the focus of attention in academic circles [2]. The scale of higher education development is divided into two ways: one is external development, mainly characterized by "expansion", relying on "external" forces to "push" or "pull". "The second is the internal development, which means that higher education institutions, as the main body of development, can improve their resources through the comprehensive use of available internal and external resources [3]. The second is internal development, which refers to a way of development in which higher education institutions, as the main body of development, can achieve organizational development goals and improve the quality of human resources training by making comprehensive use of available internal and external resources, improving resource allocation capacity, optimizing system structure, improving personnel quality, and fully exploiting the inner potential of the main body [4]. There are many indicators to measure the scale of higher education, such as the number of higher education institutions, the number of educational personnel, the number of full-time teachers, the number of enrollment, the number of students enrolled, etc. In order to reflect both the external and internal development of higher education, this paper uses the number of higher education schools, educational personnel, and full-time teachers in the last five years (2015-2019) as indicators, and uses GM $(1,1)$ model to predict the changes of these three indicators in the future years, while proposing targeted policies and testing them for accuracy, so as to analyze the realistic impact.

\section{FORECAST}

We selected from the data published by the National Bureau of Statistics of China for the years 2015-2019 the number of schools, educational personnel and full-time teachers. The table as below.

Table 1 Specific values of China's higher education indicators for 2015-2019

\begin{tabular}{|l|l|l|l|l|l|}
\hline Indicators & 2015 & 2016 & 2017 & 2018 & 2019 \\
\hline Schools & 1986 & 2025 & 2039 & 3693 & 2113 \\
\hline
\end{tabular}




\begin{tabular}{|l|l|l|l|l|l|}
\hline $\begin{array}{l}\text { Educational } \\
\text { Personnel }\end{array}$ & 2381073 & 2414934 & 2445045 & 2470372 & 2505285 \\
\hline $\begin{array}{l}\text { Full-time } \\
\text { Teachers }\end{array}$ & 1543862 & 1578131 & 1613918 & 1637508 & 1666881 \\
\hline
\end{tabular}

\subsection{Forecast of the number of schools.}

We will perform a detailed calculation of the number of schools.

Table 2 Raw data

\begin{tabular}{|c|c|c|c|c|c|}
\hline & 1 & 2 & 3 & 4 & 5 \\
\hline$x^{(0)}$ & 1986 & 2025 & 2039 & 3693 & 2113 \\
\hline$x_{(x)}^{(0)}$ & $x_{(1)}^{(0)}$ & $x_{(2)}^{(0)}$ & $x_{(3)}^{(0)}$ & $x_{(4)}^{(0)}$ & $x_{(5)}^{(0)}$ \\
\hline
\end{tabular}

From the above graph we can see that there is no

$$
x=x^{(0)}
$$

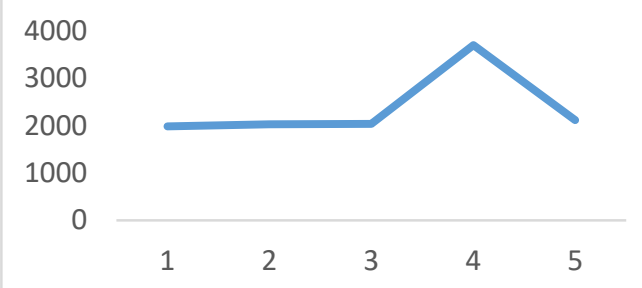

figure 1 Raw data obvious pattern in the raw data, so we establish $\operatorname{GM}(1,1)$ model.

Step 1: Job 1-AGO Generation

$$
x^{(1)}(k)=\sum_{m=1}^{k} x^{(0)}(m)
$$

According to the above equation, we get x(1) :

Table 3 A cumulative generation

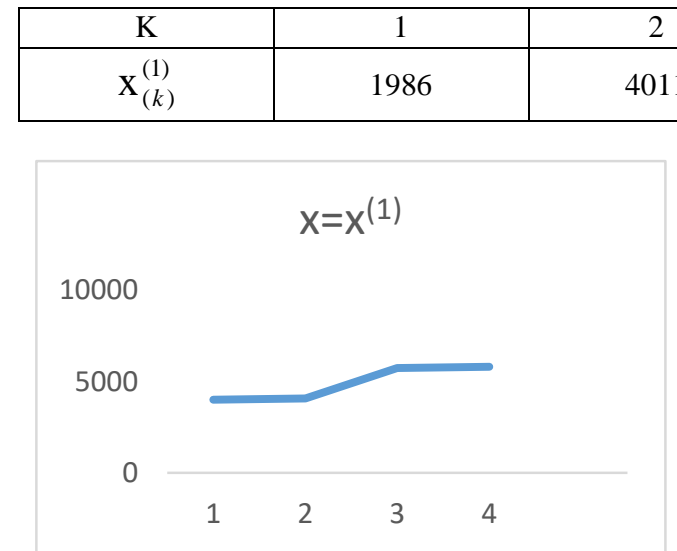

figure 2 A cumulative generation

A cumulative generation of the original data shows that $\mathrm{x}(1)$ has shown growth regularity.

Step 2: Determine the data matrix B, $\mathrm{y}_{\mathrm{N}}$

$\left(B^{\mathrm{T}} \mathrm{B}\right)^{-1}=\left[\left[\begin{array}{cccc}-2998.5 & -4037.5 & -4898 & -5769 \\ 1 & 1 & 1 & 1\end{array}\right] \times\left[\begin{array}{cc}-2998.5 & 1 \\ -4037.5 & 1 \\ -4898 & 1 \\ -5769 & 1\end{array}\right]\right]^{-1}=\left[\begin{array}{cc}0.000000012111791 & -0.00005687600972 \\ -0.000056487600972 & 0.25\end{array}\right]$

Step 4: Find the parameter column $\hat{\mathrm{a}}=\left(\begin{array}{l}a \\ u\end{array}\right)$
By parametric arithmetic (least squares estimation): 


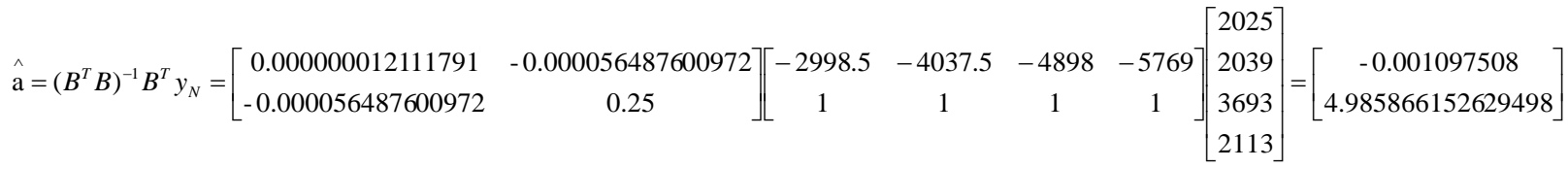

Step 5: Determining the model

Albino differential equations

$$
\frac{\mathrm{d} x^{(1)}}{d t}+a x^{(1)}=u
$$

so $\frac{\mathrm{dx}^{(1)}}{d t}-0.001097508 x^{(1)}=4.985866153$

Time-response

$$
\left\{\begin{array}{c}
\hat{x}^{(1)}(k+1)=\left(x^{(0)}(1)-\frac{u}{a}\right) e^{-a k}+\frac{u}{a} \\
x^{(0)}(1)=1986, \frac{u}{a}=\frac{4.985866153}{-0.001097508}=-4542.89656
\end{array}\right.
$$

Then $\wedge^{(1)}$ 6528.89656e-0.001097508k-4542.89656

Here the predicted value of $\mathrm{x}(1)$ is obtained and then the values of $k=1,2, \ldots, n$

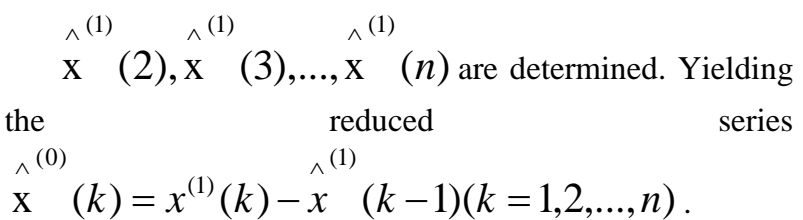

This yields a forecast for 2020 of $2918.7994,2021$ of 3124.6379.

Our suggestions are:

(1) Accelerate the transformation and development of universities and promote the reform of education supply structure;

(2) Explore the possibility of mixed ownership of universities to provide the parent universities to continue to participate in running schools;

(3) Selecting suitable investors with social power and stimulating the enthusiasm of school operation.

\subsection{Forecast of the number of educational personnel}

In the same way we can derive the educational personnel 2020 forecast as $2533897.5188,2021$ forecast as 2564635.4071 .

Our suggestions are:

(1)Strengthen the personnel management of colleges and universities. When recruiting and employing teachers, we should set up clear qualification conditions and long-term talent training plan according to the needs of discipline construction and job requirements of colleges and universities;

(2)Establish a standardized and efficient job responsibility system, carry out work task assessment, positive and negative rewards and punishments, job promotion and removal, and pay and welfare incentives.

\subsection{Forecast of the number of full-time teachers}

And full-time teachers 2020 forecast as $1697762.5193,2021$ forecast as 1728306.7168 .

Our suggestions are:

(1) As a carrier of intellectual labor, teachers in colleges and universities show different characteristics and advantages in different periods, which is the basic law of development of natural human beings.

(2) Based on these characteristics, colleges and universities can make scientific teacher allocation based on the age level and professional title of teachers from the requirement of overall economic efficiency.

\section{TESTING}

\subsection{Precision Inspection for schools}

After proposed targeted policies, we need to test the precision of these three specific policies because we cannot be sure at this point that the forecast is really reasonably valid.

We will use the residual test for accuracy prediction, and the following table shows the test for the number of schools, as follows 
Table 4 Residual test table

\begin{tabular}{|l|l|l|l|}
\hline $\begin{array}{l}\text { Generate model calculation } \\
\text { data }\end{array}$ & Actual number & Restore data & Actual number \\
\hline$\hat{x}^{(1)}(2)=1978.8384$ & $x^{(1)}(2)=4011$ & $\hat{\wedge}^{(0)}(2)=2013.4$ & $x^{(0)}(2)=2025$ \\
\hline $\begin{array}{l}\wedge^{(1)}(3)=1971.6847 \\
\hat{\wedge}^{(1)}(4)=1964.5388\end{array}$ & $x^{(1)}(3)=4064$ & $\hat{x}^{(0)}(3)=2085.2$ & $x^{(0)}(3)=2039$ \\
\hline$\hat{x}^{(1)}(5)=1957.4008$ & $x^{(1)}(4)=5732$ & $\hat{x}^{(0)}(4)=3767.5$ & $x^{(0)}(4)=3693$ \\
\hline
\end{tabular}

The error can be derived from the above table as follows.

Table 5 Error table

\begin{tabular}{|l|l|}
\hline Error & Percentage of error \\
\hline$q(k)=\left[x^{(0)}(k)-\hat{x}(k)\right]$ & $e=\frac{q(k)}{x^{(0)}(k)} \times 100 \%$ \\
\hline $\mathrm{q}(2)=11.6$ & $\mathrm{e}(2)=0.5728 \%$ \\
\hline $\mathrm{q}(3)=-46.2$ & $\mathrm{e}(3)=-2.2658 \%$ \\
\hline $\mathrm{q}(4)=-74.5$ & $\mathrm{e}(4)=-2.02 \%$ \\
\hline $\mathrm{q}(5)=-1728.5$ & $\mathrm{e}(5)=-81.8031 \%$ \\
\hline
\end{tabular}

At this point, the average relative error is $\frac{1}{4} \sum_{k=2}^{5} \mathrm{e}(k)=-21.3784 \%$.The error value is too large.

And the curve fitted by MATLAB is shown in Fig.

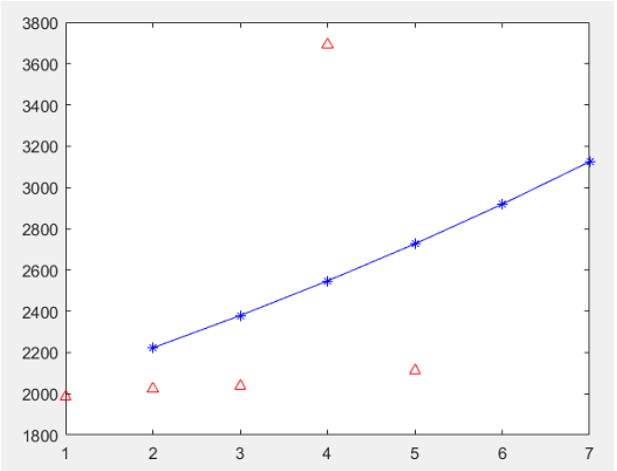

figure 3 MATLAB fit graph of schools

The post-test difference ratio was 1.0253 , and the system failed in prediction accuracy. Thus for the number of schools the proposed policy is not convincing and the validity is weak.

\subsection{Precision Inspection for educational personnel}

Using the same method, the accuracy of the prediction of the number of educational personnel is measured.

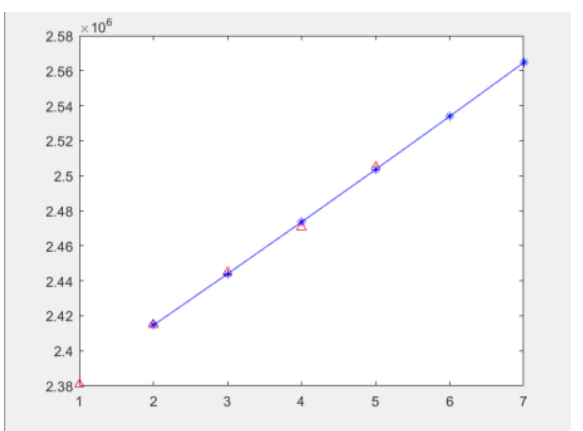

figure 4 MATLAB fit graph of educational personnel

The post-test difference ratio is 0.045246 , and the system prediction accuracy is qualified

Therefore, the validity of the proposed policy for the number of faculty members is strong and convincing.

\subsection{Precision Inspection for full-time teachers}

Likewise, the accuracy of the prediction of the number of full-time teachers is measured. 


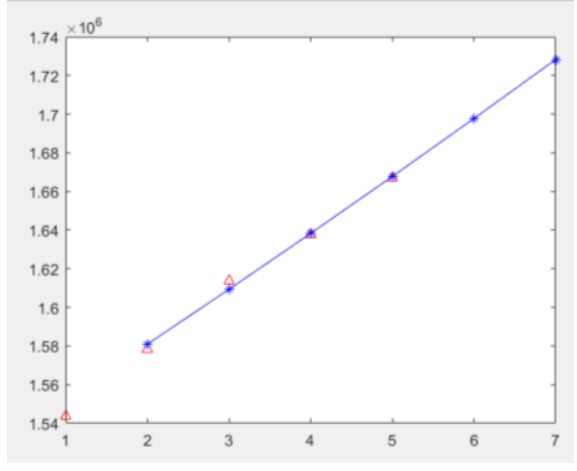

figure 5 MATLAB fit graph of full-time teachers

The post-test difference ratio is 0.064583 , and the system prediction accuracy is qualified. Therefore, the validity of the proposed policy for the number of full-time teachers is strong and convincing.

\section{CONCLUSION}

In summary, the size of higher education is still expanding. Since China's higher education has moved from mass to universalization, this can also explain why the growth in the number of higher education institutions' scale has not passed the accuracy test. And it is because China has entered the stage of popularization of higher education that the issue of higher education teachers and staff has undoubtedly become one of the important areas that must be paid attention to in order to promote the modernization of education governance system and governance capacity. In particular, General Secretary $\mathrm{Xi}$ Jinping clearly proposed in his speech at the National Education Conference that "moral education should be integrated into all aspects of education and run through all fields of education. The academic system, teaching system, teaching material system and management system should be designed around this goal, teachers should teach around this goal and students should learn around this goal [5]. This puts forward new and higher requirements for the establishment of a sound system of teachers and staff in higher education in the new era. This also explains why the scale growth of educational personnel and full-time teachers passed the accuracy test.

\section{REFERENCES}

[1] GAO Wen-hao,CUI Sheng.International Reference for the Adjustment of Higher Education Level Structure in the Popularization Phase[J].University Education Science,2021(01):111-119.

[2] Tan Zheng,Liu Yang,Tu Peng.The Characteristics of the Scale Development of China's General Higher Education and the Consideration of Its Elastic Coefficient over the Past Twenty Years[J].Jiangsu Higher Education,2021(01):57-63.

[3] XU Ji-hong.Discourse Logic of Connotative Development of Higher Education[J].Heilongjiang Higher Education Research,2018(01):19-22.

[4] ZHAO You-yuan. Focuses and Paths of the Higher Education's internal Development[J].Heilongjiang Higher Education Research,2016(01):20-23.

[5] Adhering to the development path of socialist education with Chinese characteristics to cultivate socialist builders and successors with all-round development of morality, intelligence, physical fitness and aesthetics [EB/OL].http:https://www-moe-gov-cn.webvpn.sic au.edu.cn/jyb_xwfb/s6052/moe_838/201809/t2018 0910_348145.html. 